\title{
A Teacher's Journey Through Engineering and Liberal Arts
}

\section{Prof. Keith E. Hedges, Drury University}

Keith Hedges is a registered architect and associate professor of architecture that teaches the architectural structures sequence at Drury University. Keith's teaching repertoire includes 20 different courses of engineering topics at NAAB (architecture) and architecture topics at ABET (engineering) accredited institutions. His interests involve the disciplinary knowledge gap between architecture and engineering students in higher education. Keith is the editor of the Architectural Graphic Standards, 12th Edition, Student Edition. 


\title{
A Teacher's Journey Through Engineering and Liberal Arts
}

\begin{abstract}
$\underline{\text { Abstract }}$
Have you ever wondered whether the students, the course, or the university were incompatible? This personal journey weaves its way through teaching architecture to engineering students and teaching engineering to architecture students in public and private liberal arts institutions. The problem is the mixture of conflicting wants and needs between the liberal arts and the engineering students, faculty, and programs. A personal experience narrative was performed to describe the nature of the liberal arts in engineering courses and programs in multiple settings. The accounting provides the lessons learned from teaching in higher education.
\end{abstract}

$\underline{\text { Introduction }}$

The academic field of building design becomes confounding when the variety of students, teachers, courses, programs, and intuitional types intermingle. We have a blend of engineering and architecture students, engineering and architecture courses, accrediting boards, and public and private institutions of higher education. At the simplest level, engineering students enroll in engineering courses and architecture students enroll in architecture courses in a public landgrant institution. More complex teaching and learning scenarios occur when the engineering majors take architecture courses in the Accreditation Board for Engineering and Technology (ABET) accredited degree programs and when architecture majors enroll in engineering courses in the National Architectural Accrediting Board (NAAB) accredited degree programs. The problem deepens when the setting changes from a public institution to a private liberal arts institution. In response to these scenarios, the author explored the question, "What is the personal nature of the liberal arts in engineering courses and programs from a teacher's perspective?" To examine this condition, a personal experience narrative was performed to describe the journey of being a faculty member teaching engineering and architecture courses in ABET and NAAB accredited programs, while inside public and private institutions. The primary purpose was to explore the nature of liberal arts in engineering courses and programs in multiple settings. This paper addresses persons interested in education, engineering, architecture, and liberal arts.

\section{Attitudes Towards Integrating the Two Cultures}

Physicist and novelist Snow [1] provided a stark and controversial portrayal of a polarity occurring in the mid- $20^{\text {th }}$ century British higher education system. The polarity was the separation and imbalance between the two cultures of the humanities and the sciences. He claimed that the educational system was favoring the humanities over the sciences through an antiquated notion of romanticism. He professed that this disparity would inhibit solving problems on a global scale in the modern technological world. Snow recognized the U.S. education system as a successful international example to follow.

U.S. higher education has had a long history of pursuing engineering expansion. "Every study of engineering education in this century, beginning with the Wickenden report in the 1920s, directed attention to broadening the engineering curriculum [3, p. 120].” The broadening 
included the humanities. The president of the National Academy of Engineering wrote, "Don't be tempered to crowd the humanities, arts, and social sciences out of the curriculum. The integral role of these subjects in U.S. engineering education differentiates us from much of the rest of the world. I believe the humanities, arts, and social sciences are essential to the creative, explorative, open-minded environment and spirit necessary to educate the engineer of 2020 [3, pp. 168-169]."

Two approaches pursuing balance at the degree-granting level are to adjust the entrance requirements into engineering programs and to increase the total education standard necessary for licensure. Duderstadt made a case for "undergraduate education that introduces engineering as a discipline within the context of a broad liberal education [4, p. 49]." The four-year degree would be an "entry degree into the engineering profession [4, p. v]." The degree would be preprofessional and followed by an additional practiced-based professional degree. This position is more substantial than gaining the liberal arts through a traditional general education framework. The Committee on Academic Prerequisites for Professional Practice (CAPPP) [5] sought to add one-year to the education standard for licensure. The discussion was to implement a fifth-year of education. Regardless of the ebb and flow of what does and what does not garner approval, an abundance of evidence exists that the engineering community has and continues to encourage the liberal arts at the highest levels.

\section{Accreditation Requirements}

Engineering and architecture programs voluntarily pursue accreditation to have their degrees meet the minimum education standards for licensure. ABET accredits the engineering degreegranting programs. $\mathrm{NAAB}$ accredits the architecture degree-granting programs. $\mathrm{ABET}$ and $\mathrm{NAAB}$ are organizations that identify and enforce the minimum criteria for quality assurance in the areas such as curricula, faculty, and facilities.

ABET Student Performance Criteria ABET had few, but very broad student performance criteria (SPC). ABET required that engineering programs demonstrate that graduates possessed understanding and abilities in specific areas. Some of the skills associated with the courses described in this paper include engineering performance criteria: (1) "ability to design a system ... within realistic constraints"; (2) "ability to use the techniques, skills, and modern engineering tools necessary for engineering practice"; (3) "knowledge of contemporary issues," and (4) "ability to function on multi-disciplinary teams [6, p. 2]."

For architectural engineering programs, ABET further required the students to have an "understanding of architectural design and history leading to architectural design that will permit communication, and interaction, with the other design professionals in the execution of building projects $[6$, p. 6]." Other constituents suggested more specificity in the criteria of the design process and team engagements. For the design process, the Architectural Engineering Institute (AEI) Academic Council "believes it is a professional responsibility for architectural engineers to have a basic understanding of the design process of the architects involved in the execution of building projects [7, p. 7]." For team engagements, the American Society of Civil Engineers (ASCE) Body of Knowledge (BOK) provided a more succinct example of the composition within a multidisciplinary team setting where "(1) each team member serves in a 
well-defined role in the team; (2) each team member brings a particular expertise to bear in solving the problem; and (3) the scope of the problem is sufficiently broad that no one team member could successfully solve the problem alone [8, p. 20]."

ABET addressed the liberal arts through a professional component by requiring "a general education component that complements the technical content of the curriculum and is consistent with the program and institution objectives [6, p. 2]." ABET directed that program outcomes and student assessments demonstrate that some of the skills related to the liberal arts as having: (1) "an understanding of professional and ethical responsibility"; and to (2) "attain a broad education necessary to understand the impact of engineering solutions in a global, economic, environmental, and societal context [6, p. 2]."

NAAB Student Performance Criteria The NAAB had several, but very prescriptive performance criteria. The NAAB included specific requirements and general aspirations. Structures must satisfy an independent application and an integrative application with architectural and other systems (e.g. mechanical, lighting, etc.). The independent focus required students to have an "ability to demonstrate the basic principles of structural systems and their ability to withstand gravitational, seismic, and lateral forces, as well as the selection and application of the appropriate structural system [9, p. 17]." The integrative emphasis required students to validate an "ability to make design decisions within a complex architectural project while demonstrating broad integration and consideration of environmental stewardship, technical documentation, accessibility, site conditions, life safety, environmental systems, structural systems, and building envelope systems and assemblies [9, p. 18]".

The NAAB required 45 credits of general studies through various liberal art coursework in "communications, history, humanities, social sciences, natural sciences, foreign languages, and mathematics [9, p. 21]." The NAAB specifically addressed the liberal arts performance through history and global culture where the students must possess an "understanding of the parallel and divergent histories of architecture and the cultural norms of a variety of indigenous, vernacular, local, and regional settings in terms of their political, economic, social, ecological, and technological factors [9, p. 16].” The NAAB addressed cultural diversity and social equity through an "understanding of the diverse needs, values, behavioral norms, physical abilities, and social and spatial patterns that characterize different cultures and individuals and the responsibility of the architect to ensure equity of access to sites, buildings, and structures [9, p. 16]." The NAAB included the liberal arts aspirations of: (1) comprehending people, place, and context; and (2) recognizing the disparate needs of client, community, and society [9].

\section{Emerging Trends in Architecture Education}

Emerging trends aligned with the knowledge of contemporary issues ABET criterion. Collaborative design, distance learning, building information modeling (BIM), sustainability, climate change, and the economy were a few of the emerging trends cultivated into classroom experiences. In higher education, curriculum development should include the consideration of its constituents [10]. The degree of influence follows a hierarchy where the accrediting boards have a greater impact on curricula than professional organizations, product vendors, etc. [11]. The Trends in the Professions Task Group (TPTG) and the Trends in the Education Task Group 
(TETG) informed the 2009 NAAB Conditions for Accreditation [12]. The TPTG ranked collaborative design as the third most significant industry trend [13]. The TETG reported that distance learning was the second top trend within the academy [14].

The NAAB commissioned McKinley Advisors to find "the educational needs and professional expectations of architecture students [15, p. 3]" to inform the NAAB Conditions for Accreditation. In 2011, the research group distributed a survey to invited members of the Association of Collegiate Schools of Architecture (ACSA), American Institute of Architects (AIA) and its student chapter (AIAS), and the National Council of Architectural Registration Boards (NCARB). The McKinley Advisors asked the question, "What in your opinion is the most significant development that will impact the field of architecture over the next several years [15, p. 9]?" The 2,700 respondents recognized the economy and unemployment, sustainability and environmental factors, and BIM as the three most significant developments.

The Design Futures Council annually commissions Design Intelligence to research architecture, landscape architecture, interior design, and industrial design academic programs. In the 2012 report, Design Intelligence surveyed over 277 professional practice organizations, 111 academic deans and chairs, and 2,300 students [16, p. 14]. The respondents identified sustainability and climate change, integrated design, and the speed of technological change as the three biggest concerns of the design profession [16, p. 19].

\section{$\underline{\text { Procedure }}$}

A narrative research design with a qualitative sensibility was selected to describe the personal experiences associated with the issue of liberal arts in higher education engineering courses and programs. The rationale is that a narrative study affords an opportunity to tell the story through teacher reflection [17]. The story is a chronological [17], first-person, autobiographical account [18] with prompting from archived annual review documents and subsequent validation from colleagues. The classroom settings included one public land-grant and one private institution with a mixture of engineering and architecture students in opposing degree granting programs.

The narrative context is threefold as it describes a broad timeframe and scope, and then narrows to experiences in and out of the classroom. First, the wider breadth of a life history framework allows the sharing of noteworthy events and contextualization surrounding the issue [19]. Second, the format of a personal experience story includes various occurrences of intimate to the issue, but outside of the classroom [20]. Third, the narrowing of the teacher's story addresses learning in the classroom [21]. The narrative was assigned codes where the redundant and noteworthy codes were elicited and condensed into themes [22]. For clarity, the themes are presented in the section following the teacher experiences.

\section{Teaching Experiences in Higher Education}

The teaching experiences in higher education is an excerpted, edited, and cited version of a life story of the trials and tribulations surrounding the intermingling of architecture and engineering. The experiences described here are devoted to the full-time permanent positions at public and private institutions. I have taught architectural design and technologies to engineering students, 
and architectural structures to architecture students. The former was at the University of Wyoming, a midsize Rocky Mountain land-grant public institution in a four-year, ABET accredited, architectural engineering program. The latter is at Drury University, a small Midwestern private university in a five-year professional, NAAB accredited, architecture degree-granting program, where I currently teach.

\section{Teaching in an Engineering Program at a Public Institution}

The institution's student acceptance policy had leanings toward higher education as a right through an open enrollment philosophy. The reasons were threefold. First, the students were mostly first-generation college students. Second, the institution was the only public land-grant in the state. Third, although junior college was available, the institution was the only four-year university in the state. The university may have engaged in the open enrollment as an obligation to its citizens since this was the most viable option for their higher education.

The institution's high acceptance rate created retention issues. The department relied on personality profiling as one of the measures to retain students. A senior faculty member, who was an MBTI certified professional, gave the newly minted faculty the Myers-Briggs Type Indicator (MBTI) preferences test. The test involved selecting one of two choices when confronted with a given circumstance. My responses identified that I have ENFJ (Extroverted, iNtuitve, Feeling, Judging) preferences according to Jung's four psychological functions [23]. The department wanted us to become aware that faculty most likely have different characteristics than their students and that the faculty should be cognizant of these the differences in our teaching and interactions.

The program of study required the completion of 132 credits. Of the 43 courses, two courses were one-credit, six courses were four-credits, and 35 courses were three-credits. Only one, of the four-credit courses, was a core course. The four-credit course was the capstone design experience during the last semester. The curriculum had all but one of the core courses at threecredits. The structural analysis, structural design (concrete, steel, etc.), soil mechanics, engineering materials, architectural history, architectural design, professional practice, et al. were all equally weighted considering the number of credits. The balanced credit load implied that the course content had equal importance, even though the architectural design course had five contact hours, which exceeded the 2.5 contact hours for the other three-credit classes.

Course Instruction I primarily taught the architectural design, professional practice, and building performance, required undergraduate, core courses. I was responsible for all the sections. I had the pedagogical freedom to develop content and instructional methods if the course description and the assigned accreditation criteria were satisfied.

Introductory Design Studio The introductory architectural design studio integrated the trends of building information modeling and collaborative design. The course was taught in a computer lab. The department provided each student with state-of-the art, quad-core, personal computers and dual monitors equipped with the Autodesk Revit software. The students created architectural solutions using BIM as the design tool [24] from a given building program. The projects were commonly a museum [25], theater [26], etc. with a cultural sensibility. 
The instructional method was an exploratory studio journey of discovery with a graphical emphasis. The student outcomes included spatial organizations (floor plans), visualizations (elevations), and basic detailing (sections). One observation was that BIM provided a logical application to an otherwise unscientific design journey. The studio assessments were qualitative. This created some apprehension as the grading appeared subjective. The assessment was based on a qualitative relative grading system [27, pp. 434-435]. The course contributed to demonstrating the ABET performance criteria of "ability to design a system ... within realistic constraints;" (2) "ability to use the techniques, skills, and modern engineering tools necessary for engineering practice;" and (3) "ability to function on multi-disciplinary teams [6, p. 2]."

One semester, I was the principle investigator on a national AIA Research for Practice grant [26]. The students designed a 57,500 $\mathrm{ft}^{2}\left[5,342 \mathrm{~m}^{2}\right]$ performing arts center. The fundamental premise of the grant was to make connections beyond university borders and to describe the nature of their collaborations. BIM connected three public universities and nearly 100 students. Each school played a different role in creating an architectural design response. The group activities followed the ASCE BOK for multidisciplinary team collaboration for roles, expertise, and project scope $[8$, p. 20]. The project had a sustainability component where the building had to meet Leadership in Energy and Environmental Design (LEED) standards. The LEED aspect was related to the ABET criterion of "an understanding of professional and ethical responsibility [6, p. 2]."

Building Performance The building performance class was a new course specifically developed to address sustainability topics surrounding global climate change. The course sought to strengthen the accreditation areas of ethical and professional responsibilities associated with global and societal contexts. I along the two other colleagues created the framework for the new course, sought the guidance of the curriculum committee, and gained faculty approval. This was a major undertaking since the engineering curriculum was very prescriptive and difficult to change since fewer course credits were available. I was the first person to teach the new course.

The student demographics provided a backdrop where separating fact from speculation or hyperbole was critical. Many of the students had family employed in the regional oil and coal industries. This was an indication that some of the students could be opponents of climate change. The course potentially exposed the students to new viewpoints not considered prior to college. The premise was to present proven information. The content was presented via a digital coursepack with fill-in-the-blanks on an interactive Smartboard screen. The student outcomes were mostly through examinations with some secondary homework and projects. The assessment used an absolute grading system [27, p. 433].

Professional Practice The civil and architectural engineering practice class centered on design and construction case law. The legal outcomes shaped similar language in the Engineers Joint Contract Documents Committee (EJCDC) and the American Institute of Architects (AIA) contracts. These contracts informed the responsibilities required during the design, bidding, and construction phases of building projects. The course instruction was a traditional lecture format with marker on whiteboard [28]. The student outcomes were primarily examinations. The assessment was based on a qualitative absolute grading system [27, p. 433]. 
The contracts component was related to the ABET criterion of "ability to use . . skills ... necessary for engineering practice $[6, \mathrm{p} .2]$ "

ASCE Policy 465 As I was exiting the engineering program, the ASCE was considering Policy 465. The ASCE Policy 465 [29] was an effort to increase the minimum education standard for licensure. "The four-year internship period (engineer-in-training) after receipt of the BSCE degree cannot make up for the formal educational material that would be gained from a master's degree or equivalent program [29, p. 3]." The architecture education standard has been through a similar process. Architecture currently requires a minimum of five years of education to be eligible for licensure. The problem is that several educational paths became accredited. The standard may be satisfied through [9]: (1) five-year professional architecture (bachelor) degree (150 credits), (2) five-year professional architecture (master) degree (168 credits), (3) combination of a four-year preprofessional architecture (bachelor) degree plus a two-year professional architecture (master) degree, and a (4) doctorate in architecture (210 credits). The optics are confusing to parents when recruiting new students. Engineering may eventually encounter similar problems.

\section{Teaching Engineering Courses at a Private Liberal Arts Institution}

The institution's student acceptance policy had leanings toward higher education as a privilege through strict entrance requirements. The state has three institutions with architecture programs. The two accredited programs are privately funded. The third program is unaccredited at a public university with an articulation agreement with an out-of-state university. Our private institution has a significantly lower acceptance rate and a higher graduation rate than the pubic university I taught previously. The lower acceptance rate is a result of admitting students with higher grade point averages and higher college admissions test scores. The lower rate has less, albeit traditional retention issues. Unlike the public university, the private institution does MTBI personality preference testing, but the purpose is to help identify potential career paths.

The department's retention issues occur at the end of the first semester and at the end of the second year. The preprofessional program is two years long. During the first year, the students are exposed to the architectural design studios. The rigor is far greater than any of their other courses. The students realize whether architecture is the appropriate program at this moment. The students begin the five-year, professional, masters of architecture program at the third year. Between the second and third years is an evaluation period where the faculty assess the student portfolios and the students must secure a minimum grade point average. Since we lose more students during the first year through the studio experience, most of the students earn entry into the professional program.

When I began at the private school, we were transitioning into a five-year Master of Architecture from a five-year Bachelor of Architecture degree. The board approved our application which centered on the fifth-year having a research emphasis. The program of study requires the completion of 168 credits [9]. Of our 50 courses, 41 courses are three-credits and nine courses are five-credits. A typical semester will have four three-credit classes and one fivecredit class. The architectural design studios are five-credits. The design studios have 12 weekly contact hours, which exceeds all the other courses combined totaling ten hours. The imbalanced 
credit hours and contact hours place the non-studio courses at a disadvantage. The optics sends a message that their content is not as important as the studio courses. The non-studio courses have a difficult time competing for the students' attention with the fewer available hours.

Course Instruction I am responsible for creating and teaching the structures sequence. Our curriculum contains three structures courses for nine total credits. The structures courses satisfy the independent nature of the NAAB student performance criterion for the "ability to demonstrate the basic principles of structural systems and their ability to withstand gravitational, seismic, and lateral forces, as well as the selection and application of the appropriate structural system [10, p. 17]." Structures learning also occurs in other courses such as the architectural design studio. The studio satisfies the integrative emphasis of the accreditation criteria.

Introductory Architectural Structures The introductory structures course responded to two situations. First, there was a perceived influence of the liberal arts coming from the institutional level and the faculty level. Second, the students struggled with conventional rigid body statics and deformable body mechanics as introductory content. The situations brought about dramatic change to the instructional systems design of the course.

At the institutional level, the private university is rooted in the liberal arts tradition. The architecture program began as a couple of architectural elective courses in the art department. The courses evolved and grew into an unaccredited four-year, preprofessional degree and then an accredited five-year, professional degree. Although there is no mandate integrating liberal arts into the engineering courses, a sense of loyalty exists since the birth of the program was inside the liberal arts. Furthermore, the small size of the institution places the liberal arts within a physical and academic proximity to the program.

At the faculty level, the department has a close relationship with physics. The physics department designed a unique instructional strategy specifically for the architecture students continuing into the structures and mechanical technology sequences. The course uses a teaching strategy that involves student-led, whole-class, discussions that focuses on the consensus building of concepts [30]. The narrowing of the traditional computational approaches to technology courses was reminiscent of my campus interview. A faculty member asked 'can you teach structures without math?' Whether perceived or real, I felt influenced by the history of our program and how other faculty approached the technical content at the liberal arts institution.

I developed a new instructional method to improve student performance. Having previously taught statics to engineers, I noticed the students struggling. From the architecture student perspective, the engineering content did not appear relevant to their becoming architects nor to their building designs in the five-credit studio classes. Rather than apply a consensus-building discussion format as in the prerequisite physics course, I explored various teaching strategies. I created a research project with control and experimental groups. The experimental section had a parti pris pedagogy [31] with a reverse content sequence where the central big ideas of architectural structures preceded their refinement into statics and mechanics. The instructional method is traditional lecture via marker on whiteboard. The learning outcomes are primarily homework and examinations. The assessment follows an absolute grading system [27, p. 433]. 
Capstone Architectural Structures The course originally had a research emphasis due to the accreditation shift to the five-year Master of Architecture degree. The research projects commonly dealt with building failures and natural disasters [32]. The instructional method was discussion [33]. The student work was posters and scholarly papers in the case study format. The student groups presented their posters in a forum open to the full university campus. The assessments followed a qualitative relative grading system [27, pp. 434435]. The outcomes engaged the accreditation criterion of "understanding of the parallel and divergent histories of architecture and the cultural norms of a variety of indigenous, vernacular, local, and regional settings in terms of their political, economic, social, ecological, and technological factors $[9$, p. 16]."

The research emphasis shifted towards a holistic structural design when the department sought the reaccreditation. The current capstone course requires a team solution to a single structural engineering design project. The project is a 16,000 $\mathrm{ft}^{2}\left[1,486 \mathrm{~m}^{2}\right]$ archeology center. The archeology building has a cultural, liberal arts theme. The instructor provides the program and the architectural design solution to the students. The building features two-story interior spaces, long span framing, overhangs, skylights, and intentional design conflicts between engineeringand architecture-driven preferences. The architecture students are negotiating through design choices from the perspective of being an engineer. The instructional method is the design studio format which is variant of the laboratory classroom [34]. The studio environment embraces the exploration of alternative structural solutions. The outcome is a structures book articulating the code compliant graphic and numerical solutions along with an AIA architect-consultant agreement. The assessments follow a qualitative relative grading system [27, pp. 434-435].

Alternative Avenues for Teaching and Learning I found alternative ways to engage in learning experiences with my students. The student cohorts were concurrently enrolled in the capstone structures course and the same design studio course. The design studios responded to resilience and sustainability themes through design-build. My studio colleagues led projects associated with the revitalization of a historic park at the center of a major tornado event. The projects included a volunteer tribute in the park [35] and a butterfly healing garden and overlook adjacent to the park [36]. A third project was the Solar Decathlon house competition sponsored by the Department of Energy. The outcomes were the design and construction documentation and the built products. I engaged the students during the design phase in the classroom and the build phase in the field. The projects were inclusive to the students, staff, faculty, and the administration of the institution to participate in the design and build phases. This integrated the professional architecture program and the liberal arts programs.

\section{$\underline{\text { Findings }}$}

The story was analyzed by hand though a coding process [37] to elicit themes in the form of curricular interventions and actions. Several in vivo codes such as institution, department, accreditation, and course were contracted into assessment, instruction, projects, etc. A nested target diagram illustrates the placement and their containment relative to the proximity of the influence and the activities engaged by the instructor (see Figure 1). 


\section{INSTITUTION}

\section{Higher Education as a Right}

Higher education as a right placed retention issues on the faculty

\section{Higher Education as a Privilege}

Higher education as a privilege placed perceived liberal arts influence on the faculty

\section{DEPARTMENT}

\section{Program Origin}

The program's origin placed a perceived

liberal arts influence on the faculty

\section{Program of Study}

More credits were available for meeting liberal arts needs in architecture programs than in engineering programs

\section{Contact Hours}

Disparities in contact hours implied that engineering courses are less important in architecture programs

\section{ACCREDITATION}

Source of Emerging Trends

The NAAB coalesced emerging trends from industry and society

\section{Source of SPCS}

The $A B E T$ and $N A A B$ required demonstrable student outcomes in liberal arts and engineering technology

\section{COURSE}

\section{Emerging Trends and SPCS}

Used emerging trends and SPCS (BIM, sustainability, ethical responsibility, etc.) as backdrop conditions for design projects

\section{Instruction}

Created new instructional method and found new places of learning for engineering students in liberal arts institutions

\section{Assessment}

Used quantitative absolute grading system and qualitative relative grading system

\section{Student Outcomes}

Design projects included museum, theater, archeology center, etc. with liberal arts sensibilities

Figure 1. Nested target diagram of curricular interventions. 


\section{$\underline{\text { Discussion }}$}

The primary purpose was to explore the nature of liberal arts in engineering. The author explored the question, "What is the personal nature of liberal arts and engineering courses and programs from a teacher's perspective?" To examine this question, a qualitative narrative study in the autobiographical tradition was conducted. The inquiry provided a chronological story that led to the lessons learned when confronting liberal arts and engineering.

\section{Lessons Learned}

- Select project types with a liberal arts sensibility such as a museum, theater, church, etc.

Whether the student outcome is a structural or architectural design, the project selection plays an intimate role in integrating the liberal arts. The students must become familiar with the program by understanding the needs and behaviors of the occupants. For example, when the students are designing a theater, they study the performers, the stage crew, the audience, and all the supporting functions. The students are in touch with the human experience associated with the building type [38].

- Find emerging industry and societal trends by seeking out the organizations and resources used by the accrediting boards

ABET and NAAB are good sources to unearth emerging developments, although the boards update their requirements at different intervals. ABET updates their policies and procedures manual annually, which reflects minor changes. NAAB updates their conditions every five to six years, which responds to dramatic changes. Since NAAB has more time, they can seek detailed recommendations from collateral organizations such as the AIA, AIAS, NCARB, and ACSA, internal task forces, and research groups (Design Futures Council and McKinley Advisors) that cast a broader net in soliciting information. The working drafts from the organizations are generally available online prior to being filtered by the accreditation board.

- Infuse emerging trends and the student performance criteria into the curriculum as they generally respond to the needs of liberal arts

Some of the trends possessed humanities and social sciences tendencies such as sustainability and climate change. A trend could be integrated as a project requirement. For example, a design project for a theater could require that a minimum LEED threshold be satisfied. If a trend has enough longevity, the faculty could develop a new course on sustainability or another topic.

\section{- Develop an instructional strategy uniquely suited to the characteristics of your students}

Sometimes the traditional lecture, discussion, lab, etc. may not communicate with the learners. When the students, course, or institution appears incompatible, a change might be in order. Begin with an iterative and systemic instructional model that aligns the learning objectives or outcomes and the assessment methods with an appropriate instructional design strategy. One model to consider is Analysis, Design, Development, Implementation, and Evaluation (ADDIE) 
[39] in conjunction with backward design [40]. The idea is to emphasize the desired results while developing the learning objectives simultaneously. Furthermore, the desired results should align with demonstrating student performance as required by the accrediting board. Base any changes to the course on evidence from student performance, student feedback, peer evaluation, or other suitable measures.

- Align the assessment method (relative or absolute) with the student outcomes

The architectural design outcomes for engineering students is quite different than structural engineering outcomes by architecture students. The former might be more compatible with a relative grading system that refers to a position relative to a group. The latter might be more suitable with a percentage or adjusted percentage absolute grading system. See Wright [27] for different methods of grading student achievement.

\section{- Find new and nontraditional opportunities for learning}

The NAAB integrative SPC requirement opened the door to different modes of instruction. Consider team teaching opportunities [41] or where the students can learn by building [42] such as field learning during design-build activities.

- Find creative ways to generate student interest when your course has significantly less credit hours than other concurrent courses

In programs that have five or six-credit architectural design studios, your class will be of lesser interest. You are competing for the students' attention and time. Use assessment as a means of helping students learn. Resubmitting homework or re-taking examinations are learning activities that have the direct personal benefit of improving their grades [43]. In addition, they increase the amount of time engaged with the course content.

- When an engineering course or program is borne through a liberal arts department, determine whether the influence is tangible or perceived before making curricular decisions

Stark and Lattuca recognize that "some courses and programs are connected to a wide variety of departments and programs and are influenced strongly by this interdependence [44, p. 19]." You should unravel the course or program's history and distinguish the degree of actual influence prior to curricular adjustments.

\section{Concluding Thought}

"If I had to reduce all educational psychology to just one principle, I would say this: The most important single factor influencing learning is what the learner already knows. Ascertain this and teach him [/her] accordingly." - Ausebel

Ausebel understood that learning is predominantly connected to one's prior knowledge and experiences [45, p. vi]. Regardless of the courses, programs, and institutions, analyzing (A from ADDIE) to identify the learners should remain a priority while addressing the lessons learned. 


\section{$\underline{\text { References }}$}

[1] C. P. Snow, The Two Cultures. London: Cambridge University Press, 1959.

[2] B. E. Seely, "Patterns in the history of education reform: A brief essay," in Educating the Engineer of 2020: Adapting Education to the New Century, National Academy of the Sciences, Ed. Washington, DC: The National Academies Press, 2005, pp. 114-130.

[3] C. M. Vest, "Educating engineers for 2020 and beyond," in Educating the Engineer of 2020: Adapting Education to the New Century, National Academy of the Sciences, Ed. Washington, D.C.: The National Academies Press, 2005, pp. 160-169.

[4] J. J. Duderstadt, "Engineering for a changing world: A roadmap to the future of engineering practice, research, and education," in The Millennium Project. Ann Arbor, MI: The University of Michigan, 2009.

[5] Committee on Academic Prerequisites for Professional Practice, ASCE policy statement 465: Academic prerequisites for licensure and professional practice. Reston, VA: ASCE, 2007.

[6] ABET Engineering Accreditation Commission, "Criteria for accrediting engineering programs," Baltimore, MD: ABET, Inc., Mar. 17, 2007.

[7] Architectural Engineering Institute Academic Council, "Draft commentary," ver. 1, Apr. 6, 2007.

[8] ASCE Committee on Curricula and Accreditation, "Commentary on the ABET accreditation criteria for civil and similarly named programs in the context of the civil engineering body of knowledge," ver. 3.4, Reston, VA: ASCE. May 10, 2007.

[9] National Architectural Accreditation Board, 2014 Conditions for Accreditation, Washington, D.C.: NAAB, 2014.

[10] D. M. Diamond, "Curricula and courses: Administrative issues," in Field Guide to Academic Leadership, R. M. Diamond, Ed. San Francisco: Jossey-Bass, 2002, pp. 135-156.

[11] M. Theall, "Evaluation and assessment: An institutional context," in Field Guide to Academic Leadership, R. M. Diamond, Ed. San Francisco: Jossey-Bass, 2002, pp. 225-240.

[12] National Architectural Accreditation Board, 2009 Conditions for Accreditation, Washington, D.C.: NAAB, 2009.

[13] Trends in the Professions Task Group, "Trends in the professions discussion group: Report to the NAAB," 2008 Accreditation Review Conference, 2008.

[14] Trends in Education Task Group, "Trends in education discussion group: Report to the NAAB," 2008 Accreditation Review Conference, 2008.

[15] McKinley Advisors, "National Architectural Accrediting Board, Inc.: Study of accredited architectural education: Electronic survey summary." Washington, D.C., Jan. 2012.

[16] Design Intelligence, “America's best architecture and design schools 2012," Design Futures Council, Norcross, GA: Greenway Communications LLC. Report 237, vol. 17, no. 6, Dec. 2011. 
[17] M. Cortazzi, Narrative Analysis. London: Routledge, 1993.

[18] D. J. Clandinin and F. M. Connelly, "Narrative, experience and the study of curriculum," in Cambridge Journal of Education, vol., no. 3, pp. 241-253, 1994.

[19] M. V. Angrosino, Documents of Instruction: Biography, Autobiography, and Life History in a Social Science Perspective. Gainesville, FL: University of Florida Press, 1989.

[20] D. J. Clandinin and F. M. Connelly, Narrative Inquiry: Experience and Story in Qualitative Research. San Francisco: Jossey-Bass, 2000.

[21] F. M. Connelly and D. J. Clandinin, Teachers as Curriculum Planners: Narratives of Experience. New York: Teachers College Press, Columbia University, 1988.

[22] J. W. Creswell, Educational Research: Planning, Conducting, and Evaluating Quantitative and Qualitative Research, 2nd ed. Upper Saddle River, NJ: Pearson, 2005.

[23] P. B. Myers and K. D. Myers, Myers-Briggs Type Indicators. Palo Alto, CA: Consulting Psychologists Press, Inc, 1998.

[24] A. S. Denzer and K. E. Hedges, "From CAD to BIM: Educational strategies for the coming paradigm shift," in AEI 2008: Building Integration Solutions, Denver, CO, USA, September 24-27, 2008. M. Ettouney, Ed. pp. 1-11.

[25] K. E. Hedges and A. S. Denzer, "How a collaborative architecture influences structural engineering education," in Crossing Borders: 2008 Structures Congress, Vancouver, BC, Canada, April 24-26, 2008. D. Anderson, C. Ventura, D. Harvey, and M. Holt, Eds. pp. 1-10.

[26] K. E. Hedges, A. S. Denzer, C. Livingston, and M. Hoistad, "Socially responsible collaborative models for green building design," in The AIA Report on University Research Volume 4, G. Elvin, Ed. Washington, DC: The American Institute of Architects, 2010, pp. 84-102.

[27] D. L. Wright, "Grading student achievement," in Handbook of College Teaching: Theory and Applications, K. W. Prichard and R. M. McLaran Sawyer, Eds., pp. 439-450. Westport, CT: Greenwood Publishing Group, 1994.

[28] W. J. Ekeler, "The lecture method," in Handbook of College Teaching: Theory and Applications, K. W. Prichard and R. M. McLaran Sawyer, Eds., pp. 85-98. Westport, CT: Greenwood Publishing Group, 1994.

[29] American Society of Civil Engineers, "Academic prerequisites for licensure and professional practice: ASCE policy statement 465," Oct. 8, 2001.

[30] B. E. Hinrichs, "Sharp initial disagreements then consensus in a student-led whole-class discussion," in 2013 PERC Proceedings, Portland, OR, USA, July 17-18, 2013. P. V. Engelhardt, A. Churukian, D. L. Jones, Eds. pp. 181-184.

[31] K. E. Hedges, "Introduction to architectural structures: Lessons learned from parti pris pedagogy," in 121st ASEE Annual Conference and Exposition: 360 Degrees of Engineering Education, Indianapolis, IN, USA, June 15-18, 2014. pp. 1-14. 
[32] K. E. Hedges, "The 2010 Haiti earthquake: Real-time disaster inquiry in the classroom," in 118th ASEE Annual Conference and Exposition: Your Passport to Engineering Education: Vancouver, BC, Canada, June 26-29, 2011. pp 1-13.

[33] P. J. Frederick, "Classroom discussions," in Handbook of College Teaching: Theory and Applications, K. W. Prichard and R. M. McLaran Sawyer, Eds., pp. 99-110. Westport, CT: Greenwood Publishing Group, 1994.

[34] W. H. Leonard, "The laboratory classroom," in Handbook of College Teaching: Theory and Applications, K. W. Prichard and R. M. McLaran Sawyer, Eds., pp. 155-169. Westport, CT: Greenwood Publishing Group, 1994.

[35] T. D. Sooter, N. Chikaraishi, and K. E. Hedges, "Extreme service-learning: Engaging a university design-build course with a broadcast network television show in the aftermath of the Joplin tornado" in New Developments in Structural Engineering and Construction, S. Yazdani and A. Singh, Eds., vol. 2, pp. 1463-1468. Singapore: Research Publishing Services, 2013.

[36] K. E. Hedges, T. D. Sooter, N. Chikaraishi, and M. E. Krasny, "The healing powers of nature in Joplin's Cunningham Park: Coupling design-build and civic ecology," in Grassroots to Global: Broader Impacts in Civic Ecology, M. E. Krasny, Ed., pp. 177-193. New York: Cornell University Press, 2018.

[37] R. Tesch, Qualitative Research: Analysis Types and Software Tools. Bristol, PA: Falmer Press, 1990.

[38] S. Bandyopadhyay, J. Lomholt, N. Temple, and R. Tobe, The humanities in architectural design: a contemporary and historical perspective. Abington, Oxfordshire: Routledge, 2010.

[39] R. Branch, Instructional Design: The ADDIE Approach. Berlin, Germany: Springer-Verlag, 2009.

[40] G. Wiggins and J. McTighe, Understanding by Design, 2nd ed. Alexandria, VA: Association for Supervision and Curriculum Development, 2005.

[41] B. L. Smith, "Team-teaching methods," in Handbook of College Teaching: Theory and Applications, K. W. Prichard and R. M. McLaran Sawyer, Eds., pp. 127-138. Westport, CT: Greenwood Publishing Group, 1994.

[42] W. J. Carpenter, Learning by Building, New York: Van Nostrand Reinhold, 1997.

[43] K. Bain, What the Best College Teachers Do. Cambridge, MA: Harvard University Press, 2004.

[44] J. S. Stark and L. R. Lattuca, Shaping the College Curriculum: Academic Plans in Action. Boston, Allyn and Bacon, 1997.

[45] D. Ausebel, Educational Psychology: A Cognitive View. New York: Holt, Rinehart \& Winston, 1968. 